\title{
Extended Elastic Impedance Inversion for Better Delineation of Gas-bearing Sand Reservoir, Saffron Gas Field, Offshore Nile Delta, Egypt
}

\begin{abstract}
Ali A. S. ${ }^{2 *}$, Othman AAA ${ }^{1}$, Ali $\mathrm{MF}^{1}$ and Metwally $\mathrm{F}^{3}$ ${ }^{1}$ Geology Department, Al-Azhar University, Cairo, Egypt ${ }^{2}$ Qarun Petroleum Company, Cairo, Egypt

${ }^{3}$ Geology Department, Helwan University, Cairo, Egypt

*Correspondling author: Ahmed Saied Ali, Qarun

Petroleum Company, 1 Street No. 315, New Maadi, Cairo 1160, Egypt
\end{abstract}

Received: March 09, 2021; Accepted: April 08, 2021; Published: April 15, 2021

\begin{abstract}
Extended Elastic Impedance (EEI) is a very useful seismic reconnaissance attribute. EEI logs can directly correspond to the petrophysical properties of the reservoir and the seismic. EEI reflectivity volumes can be obtained directly from the pre-stack seismic data. Better discrimination between the seismic anomaly caused by either lithology or fluid content can be utilized by applying this approach.

The concept of extended elastic impedance is used to derive the petrophysical properties and distribute the reservoir facies. The study area was a Pliocene gas field, that lies in the deep marine, Offshore Nile Delta, Egypt. The workflow is simple, efficient, and uses very few inputs. We started with the fluid/ lithology logs and investigated the optimum projection in the intercept/gradient domain. Then, we used the conditioned angle stacks, to calculate the intercept/ gradient volumes, using Shuey's two-term Approximation. The intercept and gradient volumes are converted directly to the fluid and lithology 3D volumes, without any of the pre-stack inversion constraints. The outputs were tested using a blind well and the correlation exceeds $80 \%$. The results show that the EEI is a worthy effort to highlight the difference between the reservoir and nonreservoir sections, to identify the hydrocarbon area.
\end{abstract}

Keywords: Extended Elastic impedance; Seismic inversion; Wwater saturation, Saffron field, Nile delta

\section{Introduction}

The area of interest includes Saffron field, which lies in the West Delta Deep Marine (WDDM) concession, 60-120 km offshore in the deepwater of the present-day Nile Delta [1] (Figure 1). Saffron field is a Pliocene submarine delta slope canyon system, with complex turbiditic channel-levee reservoirs [2].

The Nile Delta lies within the unstable shelf, which is characterized by a thick sedimentary section covering the high basement relief due to block faulting. It is affected by minor compression folds trending (NNE-SSW) which is related to the Laramide phase of the Alpine Orogeny. The sedimentary succession of the Nile Delta is characterized by the cyclicity that began in the Miocene time with a very thick section of Late Tertiary-Quaternary sediments indicating a rapid and continuous deposition in a subsiding basin. This section consists mainly of shale with thin sandstone intercalations (Figure 2).

Saffron field was discovered by the Saffron-1 exploration well in 1998 by BG and appraised by Saffron- 2 .

The reservoir consists of a succession of sandstones and mudstones, organized into a composite upward-fining profile. Sand bodies include laterally amalgamated channels, sinuous channels, channels with frontal splays, and leveed channels, and are interpreted to be the products of deepwater gravity-flow processes [2]. The Saffron channel system is oriented NNW-SSE to N W-SE (Figure 3) and its width ranges from $5 \mathrm{~km}$ to $10 \mathrm{~km}$ and is approximately $25 \mathrm{~km}$ in length. There are almost $40 \mathrm{~m}$ of pay gas sand, out of $150 \mathrm{~m}$ gross thickness of the reservoir, with an average porosity of $25 \%$ and an average Sw of $37 \%$.

\section{Methodology}

The available data are classified into well logs and pre-stack 3D

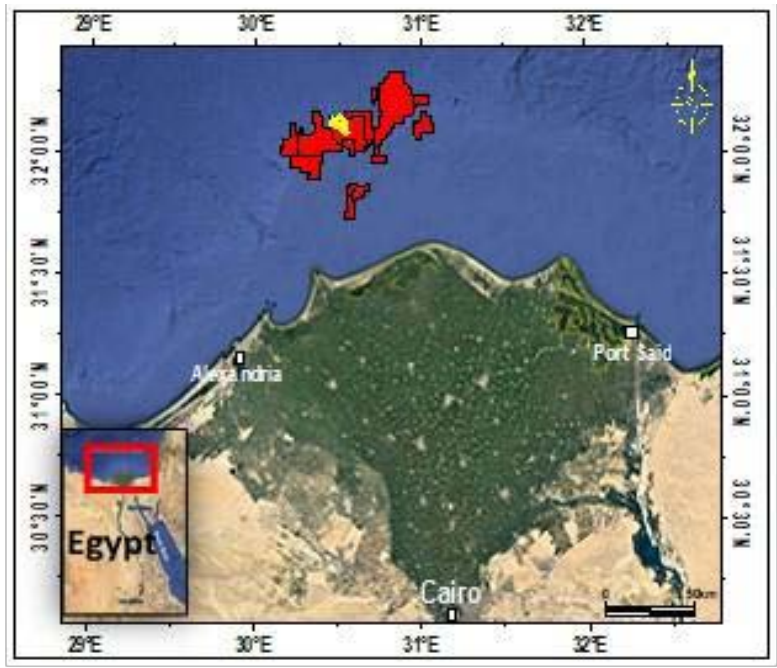

Figure 1: Location map of the Saffron field (in yellow) in the West delta deep marine concession WDDM (in red) (modified from Google Earth).
Citation: Ali AS, Othman AAA, Ali MF and Metwally F. Extended Elastic Impedance Inversion for Better Delineation of Gas-bearing Sand Reservoir, Saffron Gas Field, Offshore Nile Delta, Egypt. Austin J Earth Sci. 2021; 4(1): 1023 


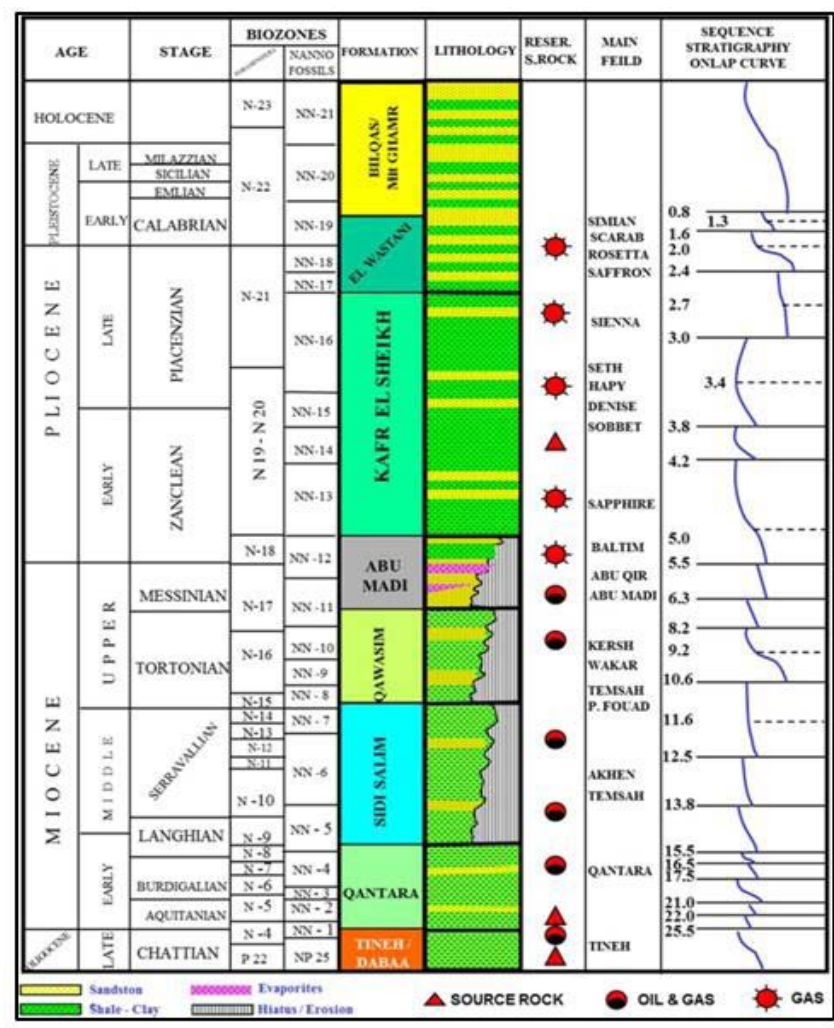

Figure 2: Stratigraphic succession of the Nile Delta and the hydrocarbon system for the main fields. Modified from [3].

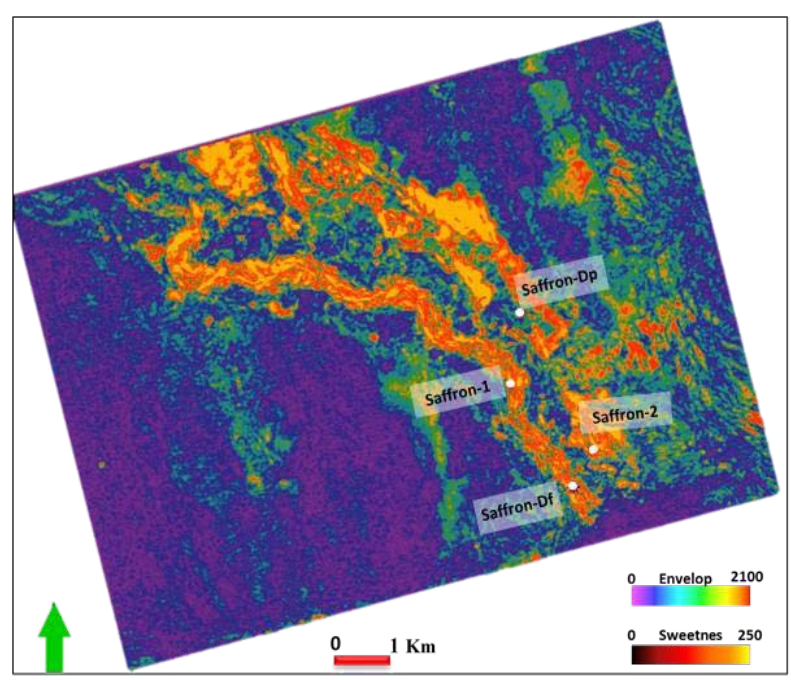

Figure 3: Reflector strength attribute extracted below the top of the channel and illustrates the orientation of the channel and the available well data.

seismic volume data. The obtained well logs include Gamma-Ray (GR), Resistivity (Rt), P-wave velocity $\left(\mathrm{V}_{\mathrm{p}}\right)$, S-wave velocity $\left(\mathrm{V}_{\mathrm{s}}\right)$, and density $(\rho)$ logs, in addition to the calculated Petrophysical logs which are water saturation $(\mathrm{Sw})$, and shale volume $\left(\mathrm{v}_{\text {shale }}\right)$ logs. three wells will be involved in this study, and another one will be used as a blind QC well.

The Workflow for the Extended Elastic Impedance (EEI) is

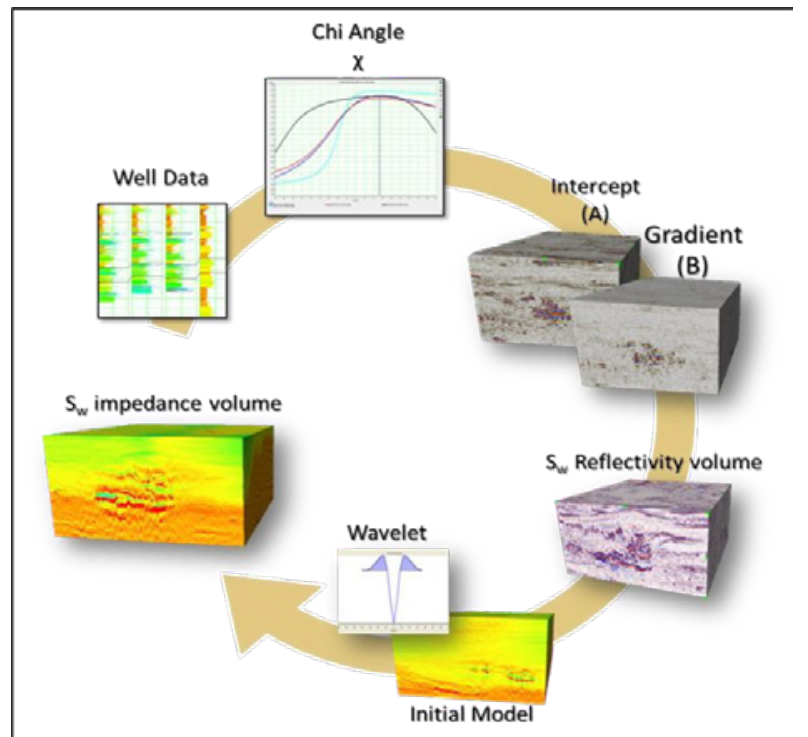

Figure 4: Extended Elastic impedance workflow Othman et al., [3].

shown in (Figure 4). The first step is to load and QC input 3D seismic data and water saturation logs, then perform EEI log correlation at each well to determine the best chi angle at which we got an optimal correlation of EEI log and the Sw log. Figure 5 shows that the high correlation for $\mathrm{Sw}$ is associated with approximately specific chi for all wells and the average correlation is $80 \%$ observed at a chi angle of approximately $28^{\circ}$. Conditioning the seismic data should be applied carefully, to give a meaningful result. After conditioning, first, we created the intercept and gradient volumes, applying the two-term AkiRichard approximation, because there is no wide-angle range. Second, we created a reflectivity volume at the chi angle, that obtained previously from the well data, by applying the following equation:

$R_{s}=A \cos x+B \sin x[4]$

where $\mathrm{R}_{\mathrm{s}}$ is the scaled reflectivity, $\mathrm{A}$ is the intercept, $\mathrm{B}$ is the gradient and $x$ : is the chi angle.

Third, we estimated the wavelet from the created reflectivity volume, before creating the synthetic trace, to make a well-to-seismic

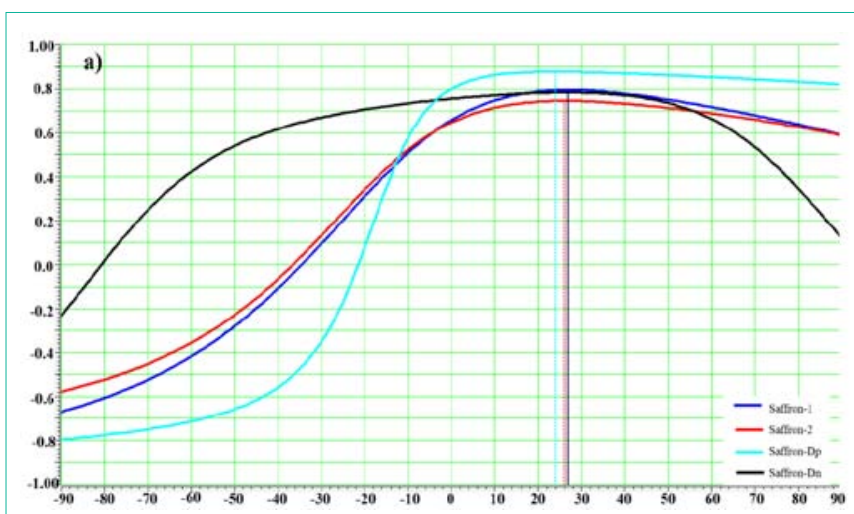

Figure 5: Illustrates the correlation coefficients between the Sw curve and $E E I$ log, for a range of values of $X$, the highest correlation occurs at $X=28^{\circ}$, is $88 \%$ at Saffron -Dp while the lowest correlation is $72 \%$ at Saffron-2, and $80 \%$ and $75 \%$ at Saffron- 1 and saffron -Dn, respectively. 


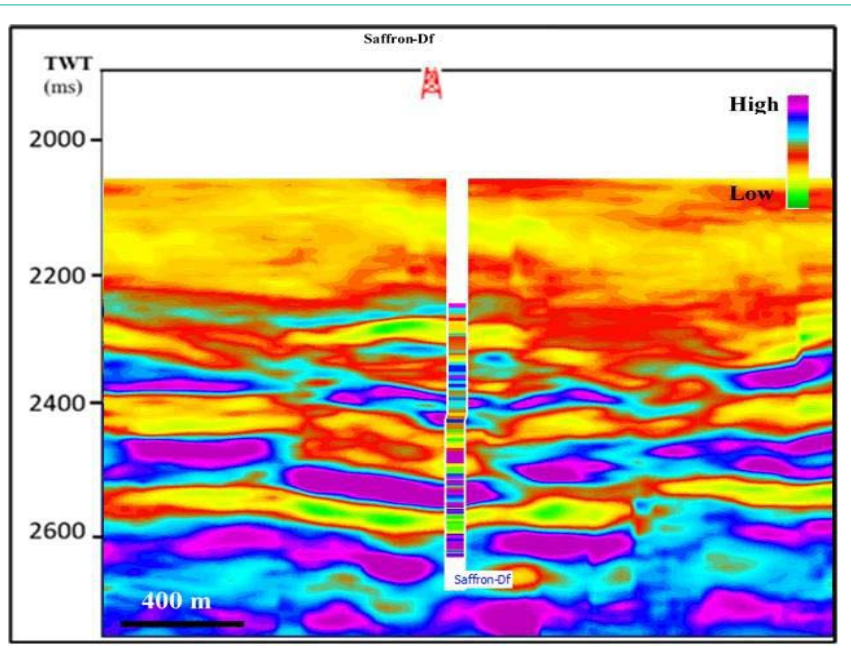

Figure 6: Seismic section passing through the resulted $E E I$ at $x=28^{\circ}$ volume of (Sw), as comparing its results to the calculated Sw log at the blind well.

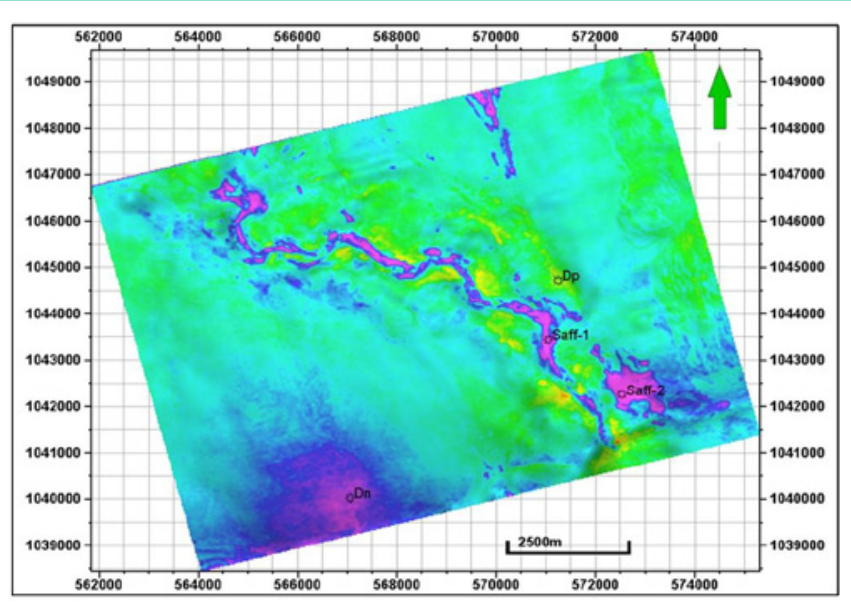

Figure 7: Minimum Amplitude extraction on reservoir zone on Sw impedance volume showing the distribution of the gas saturation.

tie at the optimized chi angle, with the corresponding trace at the reflectivity volume, which is considered as a good measure of the wavelet and chi angle estimations. Then, we built an initial model, using the EEI logs created at angle $28^{\circ}$ to invert that volume, to get a $3 \mathrm{D}$ cube for the water saturation property distribution for the reservoir.

\section{Results}

For QC purposes, we kept one well away in our study, to use it as a QC well for the results. The blind well is Saffron-Df, which lies to the south of the study area. The correlation coefficient between the actual Sw log and the calculated water saturation is 0.71 , we compared the results of the $3 \mathrm{D}$ water saturation volume at the blind well location as can be seen in Figure 6, where the distribution of the saturation will give an insight to the charged sand bodies (Figure 7).

\section{Conclusion}

Saffron field has a complex largely channelized fill, with multiple phases of re-incision, and was probably active over a considerable period. The Extended Elastic Impedance (EEI) has successfully predicted the $3 \mathrm{D}$ volume of water saturation, which is considered as one of the required elements for reservoir modeling.

The EEI workflow was straightforward and non-complicated, which starts with identifying the Chi angle that corresponds to the water saturation, to produce reflectivity volume of the property. The last step is to invert the latter volume into the required petrophysical property (Sw). Results show a good correlation to the actual saturation, which encourages to be applied on the same slope channel systems of clastic reservoirs.

\section{Acknowledgment}

The authors thank the Egyptian General Petroleum Corporation (EGPC) and Rashid Petroleum Company (RASHPETCO) for permission to publish this study and for providing the data.

\section{References}

1. Mohamed IA, Shenkar O, Mahmoud H. Understanding reservoir heterogeneity through water-saturation prediction via neural network-A case study from offshore Nile Delta: The Leading Edge. 2017; 36: 298-303.

2. Cross NE, Cunningham A, Cook RJ, Taha A, Esmaie E, Swidan NE. Threedimensional seismic geomorphology of a deep-water slope-channel system: The Sequoia field, offshore West Nile Delta, Egypt: AAPG Bulletin. 2009; 93: 1063-1086.

3. Othman A, Metwally F, Fathy M, Saied A. Characterizing complex slope channel reservoirs applying Extended Elastic impedance, Saffron gas field, offshore Nile Delta, Egypt. The Leading Edge. 2021; 40: 151a1-151a7.

4. Whitcombe DN, Connolly PA, Reagan RL, Redshaw TC. Extended elastic impedance for fluid and lithology prediction. Geophysics. 2002; 67: 63-67. 